\title{
NUMERICAL ANALYSIS OF RIVETED LAP JOINT USED IN AIRCRAFT STRUCTURES
}

\author{
Wojciech Wronicz \\ Jerzy Kaniowski \\ Institute of Aviation, Warsaw, Poland
}

\begin{abstract}
The paper presents the results of FEM analysis of two rivet lap joints loaded with tension. The joint consists of two sheets with dimensions of $125 \times 60 \mathrm{~mm}$ and nominal thickness of $1.2 \mathrm{~mm}$ made of 2024-T3 clad alloy ASNA 3012 and two rivets (fig. 1). The countersunk rivets made of PA25 alloy were used. The diameter of the rivets was $3,5 \mathrm{~mm}$ and angle $120^{\circ}$, according to the $B N$ 70/1121-05 standard.

Due to its symmetry, only a half of the joint was analysed. Nonlinear material models were used and contact phenomena between sheets, rivets and tools were taken into account. The analysis involved the riveting process as well as tensile loading of the joint. MSC MARC software was used.

The article presents the numerical analysis of the joint. The work of a rivet was studied. The results obtained up to date were discussed as well as the difficulties encountered. Experimental verification of the calculation with strain gauges is planned.

The financial support from Ministry of Science and Higher Education under the contract No. 59/EUR/2006/02 is gratefully acknowledged.
\end{abstract}

\section{INTRODUCTION}

Riveted joints have been widely used in aviation for a long time. They are also the subject of much research and there are numerous works devoted to this issue ([2, [3). This is due to the fact that very often rivet holes are places where fatigue cracks initiate, which is crucial for fatigue life as well as safe operation requirements. Nevertheless, the work of riveted joints is not sufficiently understood and requires further research. The article concerns the numerical analysis of the riveted lap joint. This kind of joint very often occurs in passenger aircraft fuselages. The study was carried out within the EUREKA-IMPERJA project E! 3496 entitled "Improving the Fatigue Performance of Riveted Joints in Airframes". The project aims at improving fatigue performance of joints by working out the optimal riveting process parameters as well as rivet and joint geometry, and improving accuracy of fatigue estimating methods.

\section{THE OBJECT OF ANALYSIS AND NUMERICAL MODEL}

The paper presents current results of FEM analyses of two rivets lap joint loaded with tension. The study includes the riveting process as well as tension of the joint. The joint consists of two sheets with dimensions of $125 \times 60 \mathrm{~mm}$ and nominal thickness of $1.2 \mathrm{~mm}$ made of 2024-T3 clad alloy ASNA 3012 and two rivets (fig.1). The countersunk rivets made of PA25 alloy were used. The diameter of the rivets was 3,5 mm and angle $120^{\circ}$, according to the BN-70/1121-05 standard. 
The calculations refer to the specimen which was made at the PZL Mielec and subjected to a fatigue test at the Institute of Aviation (fig. 2).

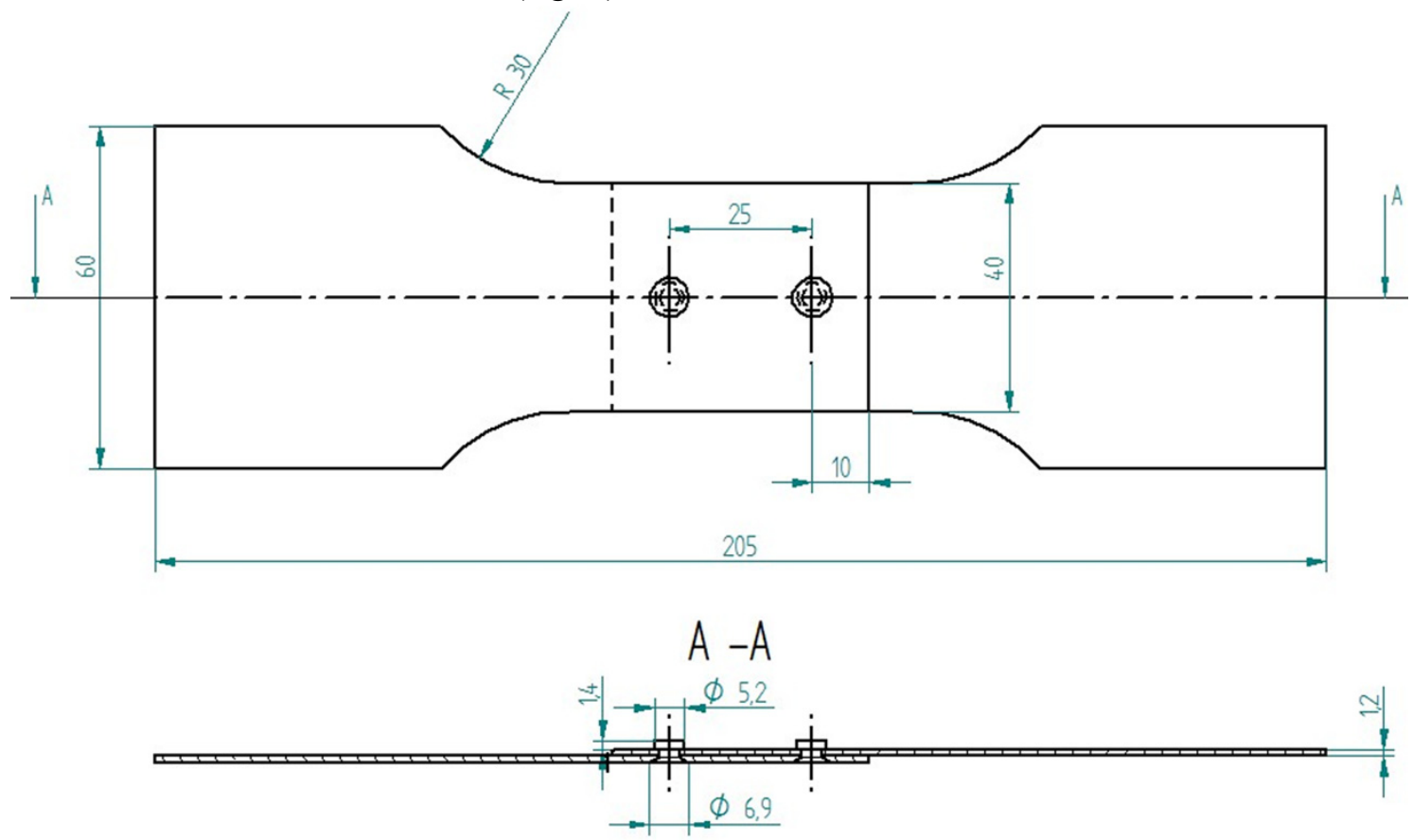

Fig. 1. Riveted lap joint specimen

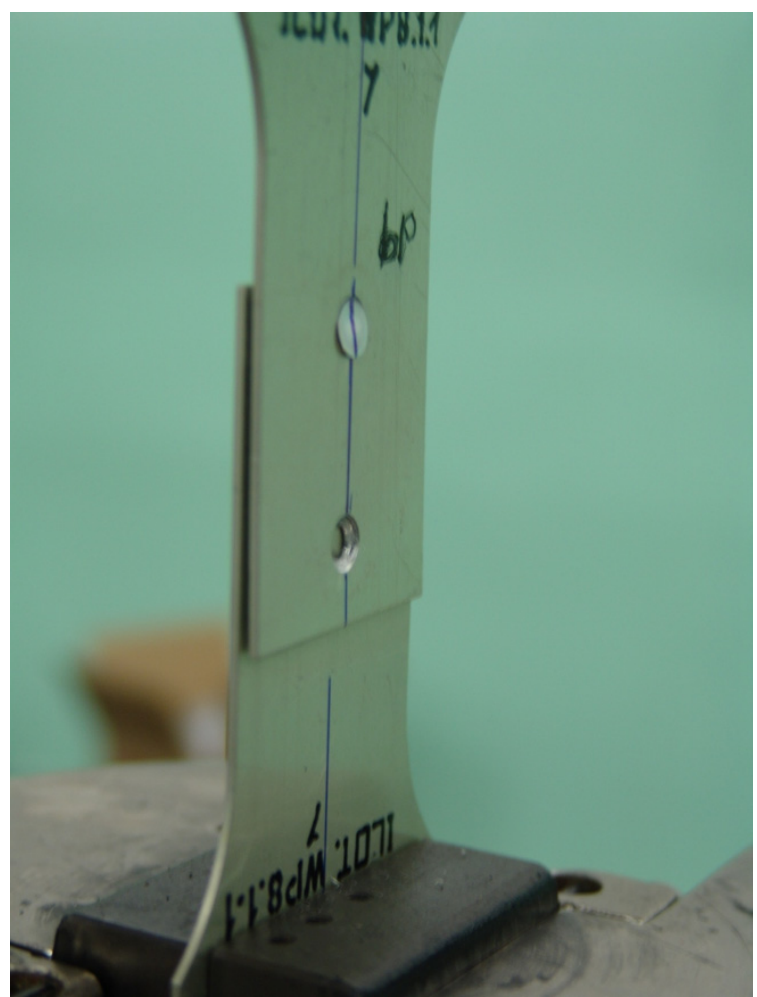

Fig. 2. The specimen on a testing machine

Due to the symmetry, only a half of the joint was analyzed. The change of the specimen width near the grip section was neglected. A rectangular shape of sheets was assumed (fig. 4). The length of the first (presented here) model was limited to the central part of the specimen, where edges are parallel. This affects secondary bending (caused by the eccentricity of the joint), however the presented model was just a test model and as such it does not exactly reflect the real process. 
The FEM model was created with linear, solid elements. The MSC MARC solver was used. The preparation of the model as well as post processing were made with the MSC PATRAN and MARC MENTAT software. The model consists of 73092 eight-and six-node solid elements (Hex 8 and Wed6) and 64300 nodes. Nonlinear material models were used for sheets and rivets. A linear variation of $\sigma(\varepsilon)$ graphs between origin, yield point and ultimate strength point was assumed. Above the ultimate strength point, the ideal plastic material model was employed. The material properties used in calculation are presented in fig. 3 and table 1 (based on [1]).

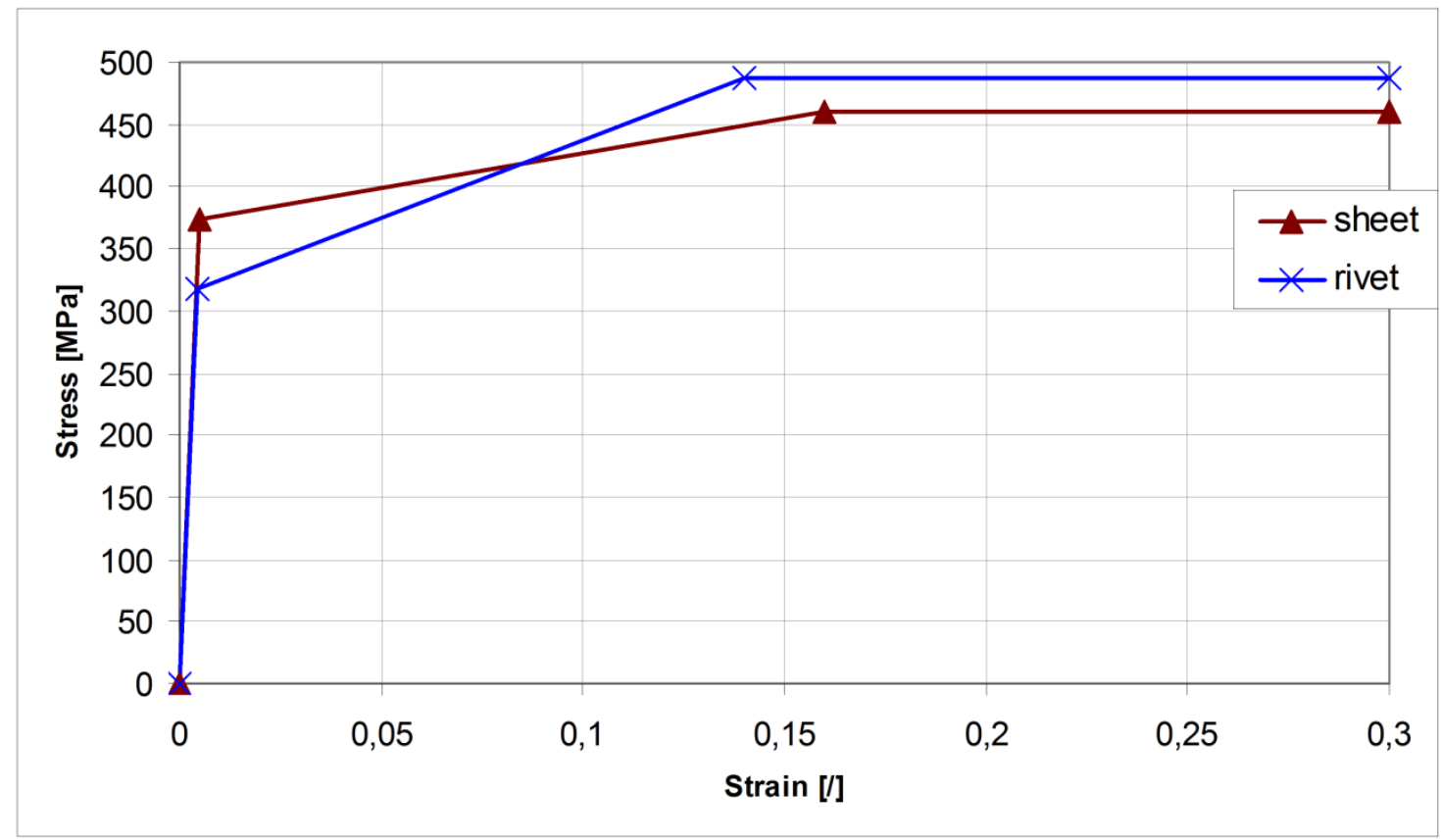

Fig. 3. Material models ([1])

Table 1. Material properties [1]

\begin{tabular}{|l|c|c|c|c|}
\hline & $E[\mathrm{MPa}]$ & $\begin{array}{c}\mathrm{Sy} \\
{[\mathrm{MPa}]}\end{array}$ & $\begin{array}{c}\mathrm{Su} \\
{[\mathrm{MPa}]}\end{array}$ & $\mathrm{A}[/]$ \\
\hline Sheet & 72000 & 374 & 460 & 0,16 \\
\hline Rivet & 72000 & 318 & 488 & 0,14 \\
\hline
\end{tabular}

The model consists of two plates and two rivets. These elements are defined as a deformable contact body. In addition, four flat rigid (undeformable) surfaces were defined. These surfaces simulate the hold-on and press punch for both rivets. The model is shown on next page in fig. 4 . 


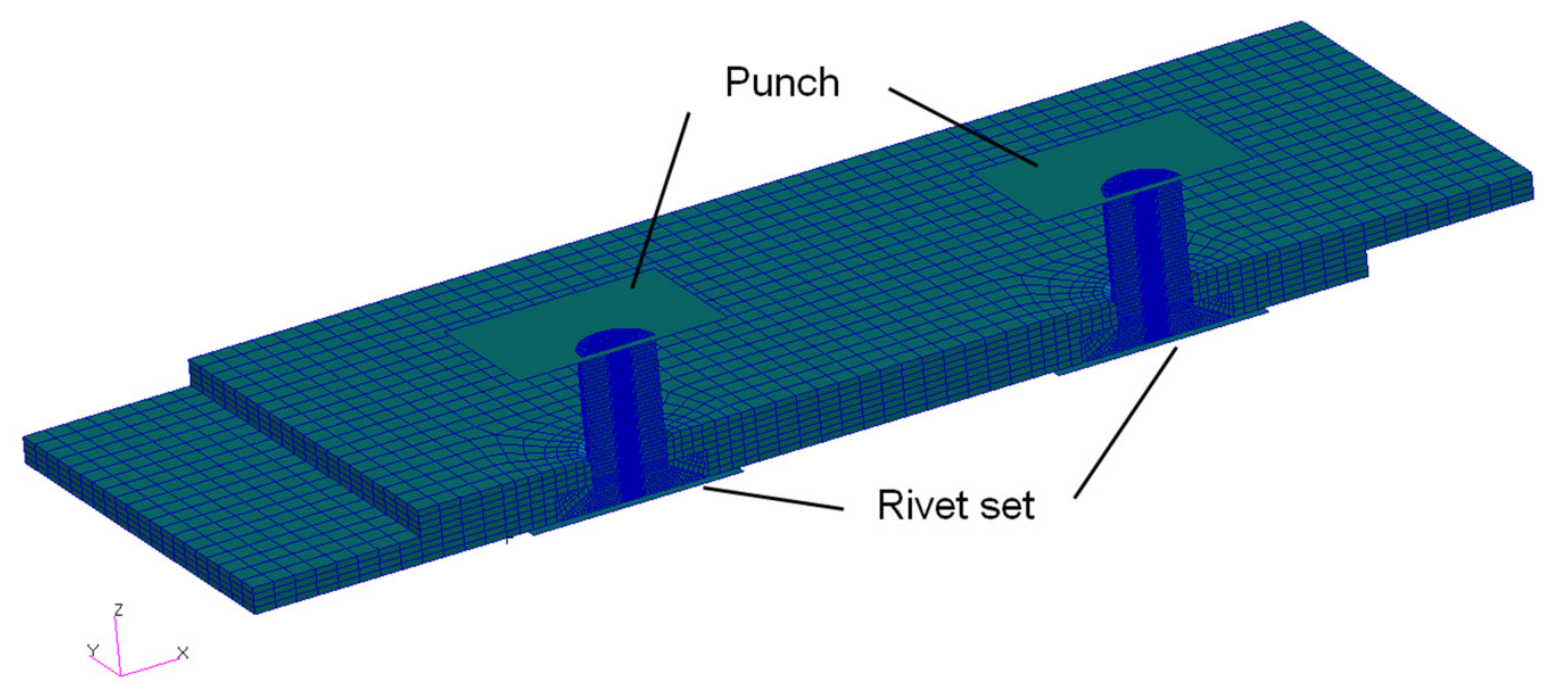

Fig. 4. Preliminary FEM model of the joint

The boundary conditions were defined in such a way as to reproduce the manner of fitting the specimen into the testing machine. At one end of the sheet (left in fig. 4), all nodes were fixed. At the right end, displacements in $\mathrm{y}$ and $\mathrm{z}$ axis directions were restricted. Only displacements in $\mathrm{x}-$ axis direction (direction of tension) remained possible. $\mathrm{X}$ displacements of all nodes at the right end of the upper sheet were tied with an MPC element. This makes all these nodes move together as in the testing machine. Such boundary conditions were applied during the whole analysis.

There are two phases of the analysis - the riveting process and tension of the joint. At the first stage, the rivet sets remain motionless while the punches move down (towards the negative z-axis direction), form the driven heads, and come back to the initial positions. Then the rivet sets are moved away. During the first calculations, both punches moved simultaneously. Then the shape of the driven heads was unphysical, similar to the reversed cone. In further calculations, the rivets were upset sequentially. This allowed gaining reasonable results (fig. 6).

At the second stage, the joint was loaded with tension. Pressure of $-65 \mathrm{MPa}$ was applied to the right end of the upper sheet. The applied boundary conditions are shown schematically in figure 5 .

a.

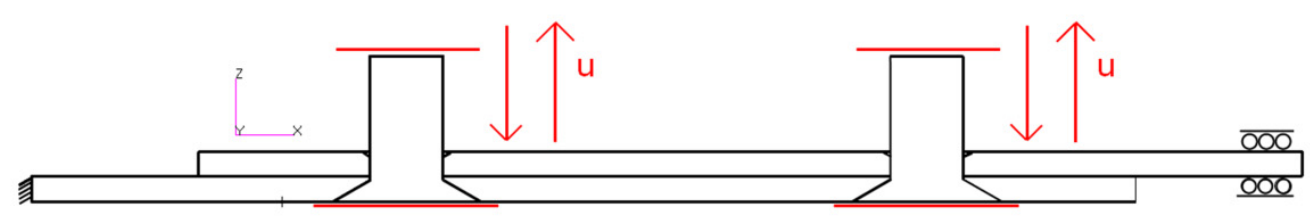

b.

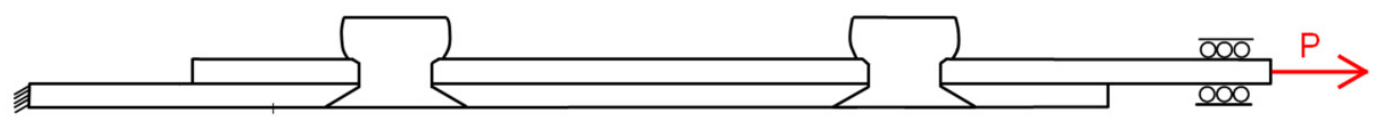

Fig. 5. Boundary conditions a) riveting process, b) tension of the joint 


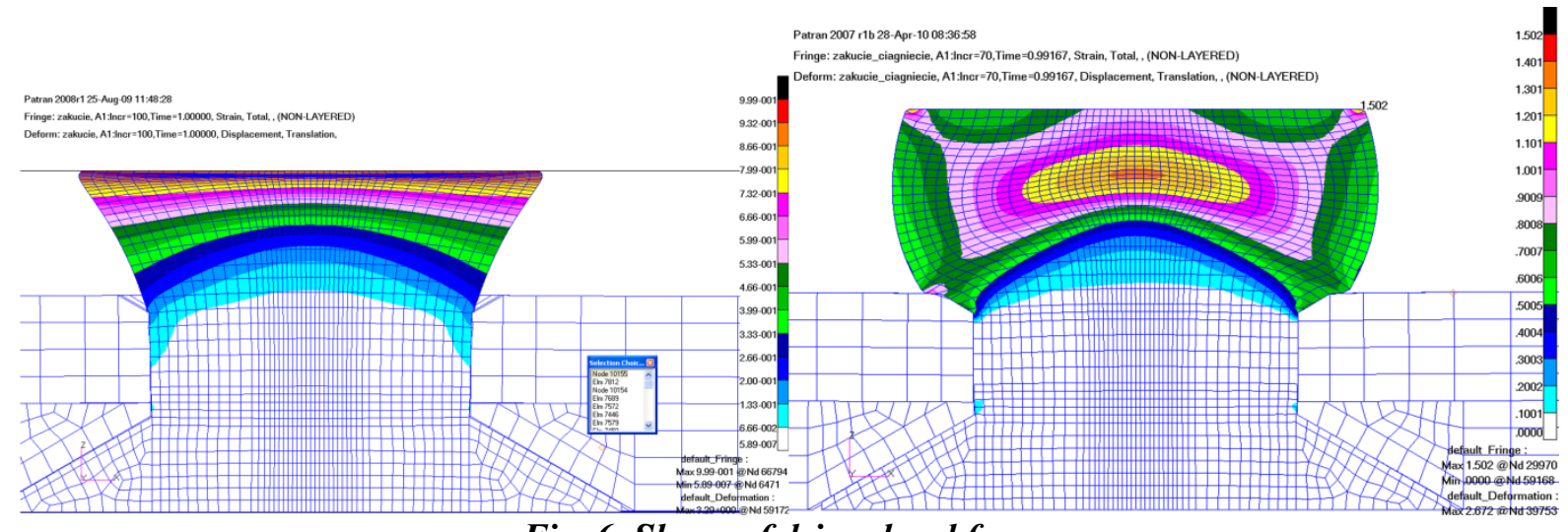

Fig. 6. Shape of driver head from

a) simultaneous b) sequential riveting process FEM simulation

\section{RESULTS}

The successful analysis of the riveting process and tension of the joint up to $61 \mathrm{MPa}$ was completed with the preliminary model (fig. 4). Above this value of tension stress convergence was not obtained. Both the shape of the driven heads and the deformation of the rivets during tension are correct. During tension of the joint the rivet is penetrated by the outer sheet (with countersink). Figure 7 presents the equivalent stresses (Huber Mises Hencky) in the joint after the riveting process (a) and at the end of the analysis (b). In fig. 8-9 there are shown the same stresses (HMH) and deformations in the vicinity of the rivets. 
a.

Patran 2007 r1b 13-Jan-10 17:51:45

Fringe: zakucie_ciagniecie, A1:Incr=260,Time=2.36375, Stress, Global System, von Mises, At Layer 1 Deform: zakucie_ciagniecie, A1:Incr=260,Time=2.36375, Displacement, Translation,

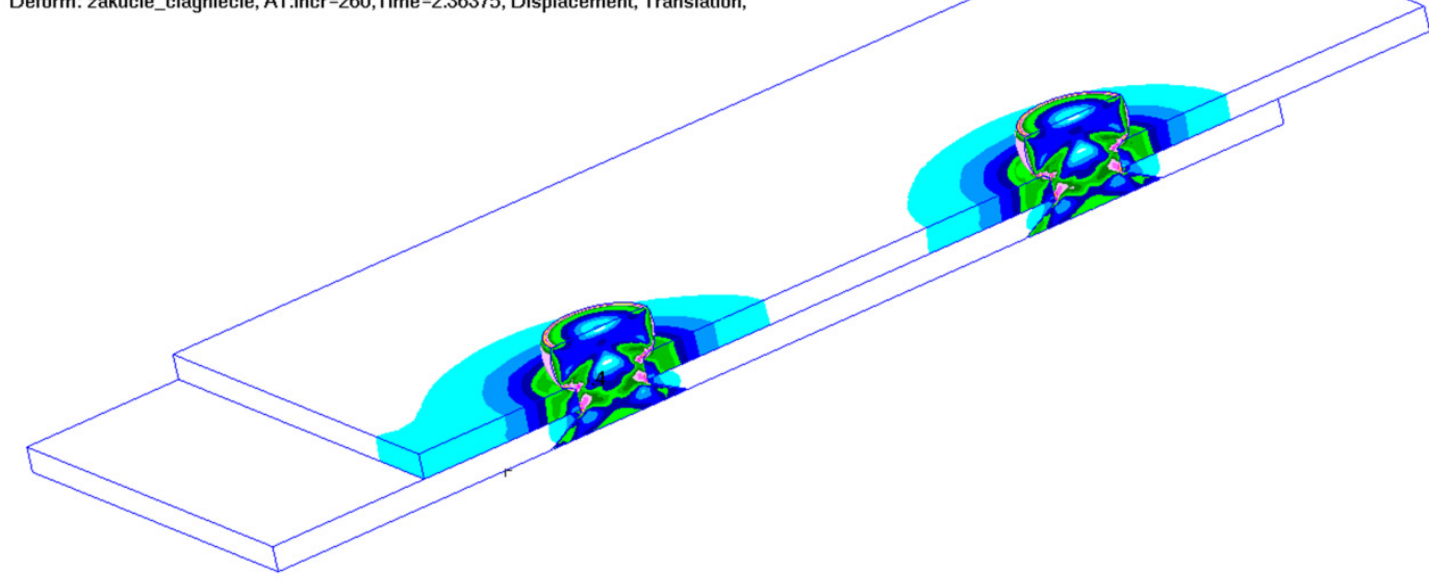

default_Fringe :
$\operatorname{Max} 720.4 @$ Nd 2885

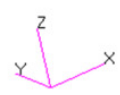

Min.0292@Nd 6476

default_Deformation :

Max2.67+000@Nd 39753

b.

Patran 2007 r1b 13-Jan-10 17:50:29

Fringe: zakucie_ciagniecie, A1:Incr $=400$,Time $=3.34562$, Stress, Global System, von Mises, At Layer 1

Deform: zakucie_ciagniecie, A1:Incr=400,Time=3.34562, Displacement, Translation, , (NON-LAYERED)

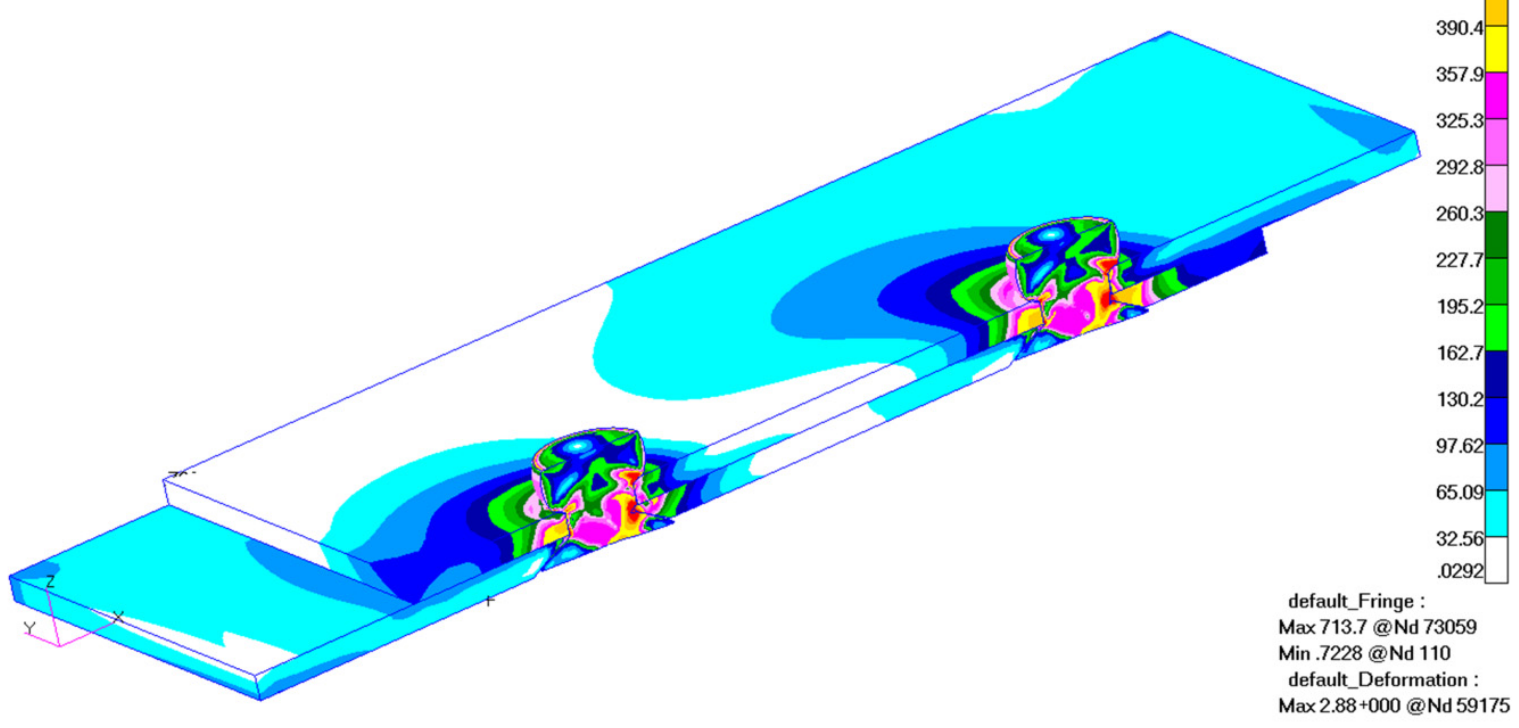

Fig. 7. Equivalent stresses (HMH) in the joint a) after riveting, b) after tension of the joint 


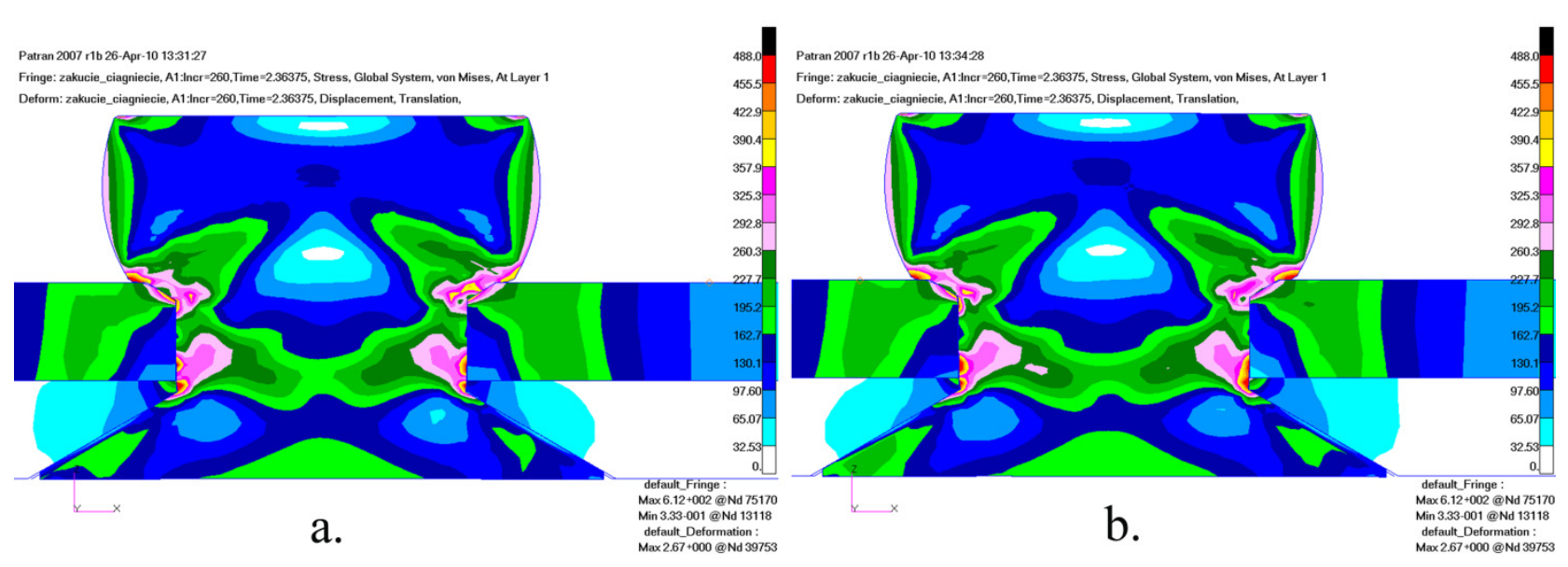

Fig. 8. Equivalent stresses (HMH) in the vicinity of the rivet a) no 1, b) no2 after the riveting process

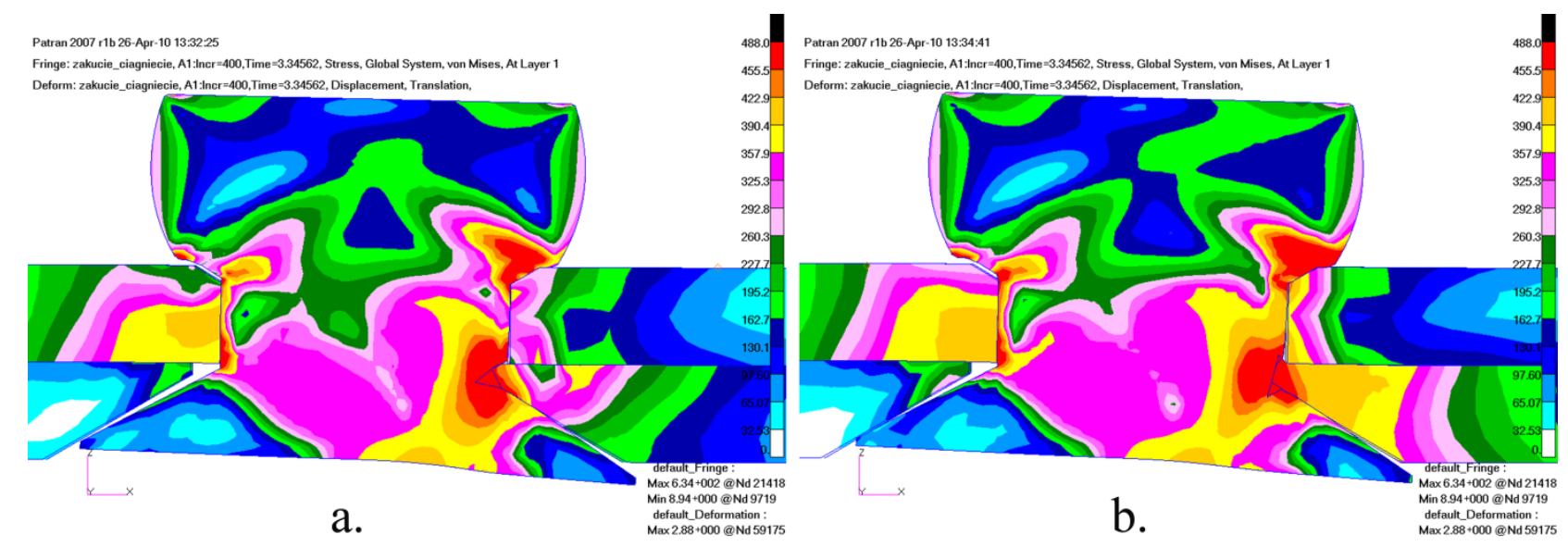

Fig. 9. Equivalent stresses (HMH) in the vicinity of the rivet a) no 1, b) no2 after tension of the joint

A significant stress concentration can be observed on the corners under the driven heads. What is conspicuous is quite big areas where stress exceeds ultimate strength. This shows that the verification of the calculation is necessary. Also, there can be seen unfavourable influence of countersink on the stress system in the outer (lower) sheet after the riveting process. In the inner sheet, the range where stresses are considerable is quite large while in the outer sheet stress is substantial only very close to the cylinder part of the hole.

Figures 10-11 present graphs of the Sx stresses (in the tension direction) on the specimen axis, on outer sheet and the manufactured head of rivet 1 , for several values of the applied tension. The highest value occurs on the edges of the rivet manufactured heads. In the graph shown in fig. 11, after the riveting process there are compressive Sx stresses (here $\mathrm{x}$ direction is identical with radial direction). The highest value can be found in the central part, under the rivet shank. During tension, the central zone, shifted slightly from the axis of the rivet, can be distinguished. In this zone, compressive stresses risen during tension. On the right and the left side of this zone, for $\mathrm{x}$ coordinate between about -2 and $-0,5 \mathrm{~mm}$, compressive stresses decrease and then change the sign and become tensile. On the left side of the graph in fig. 11, for x coordinate less than about -2 , compressive stresses firstly increase and then decrease almost to zero or even become tensile. When the applied load reaches 52,5 MPa, stresses on quite a big part of the manufactured the head are almost constant. This can be seen also in figure 12, which shows Sx stresses during tension of the joint, on selected nodes lying on manufactured head of rivet 1, on the specimen symmetry plane. 


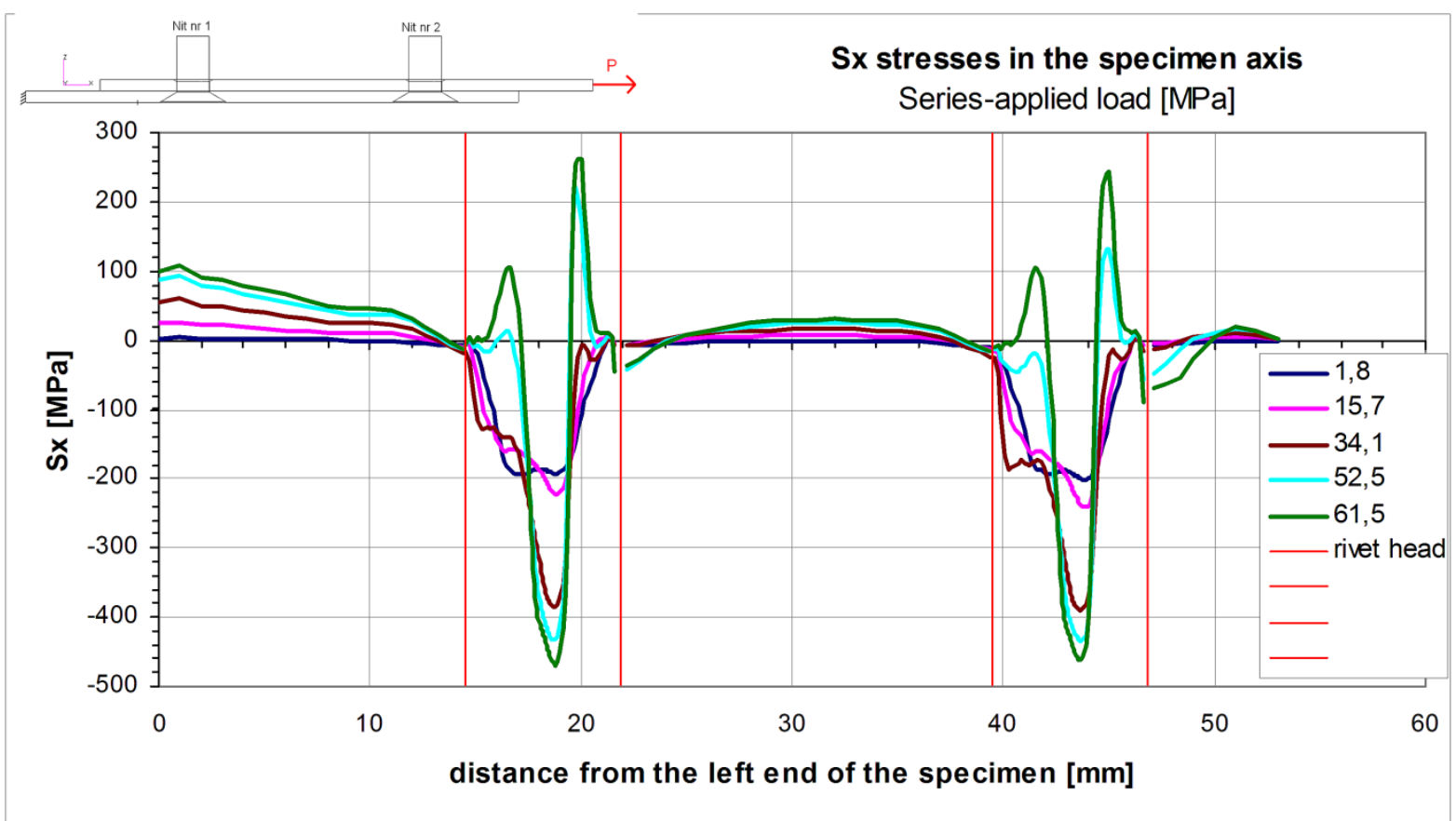

Fig. 10. Sx stresses (in tension direction) on the specimen axis

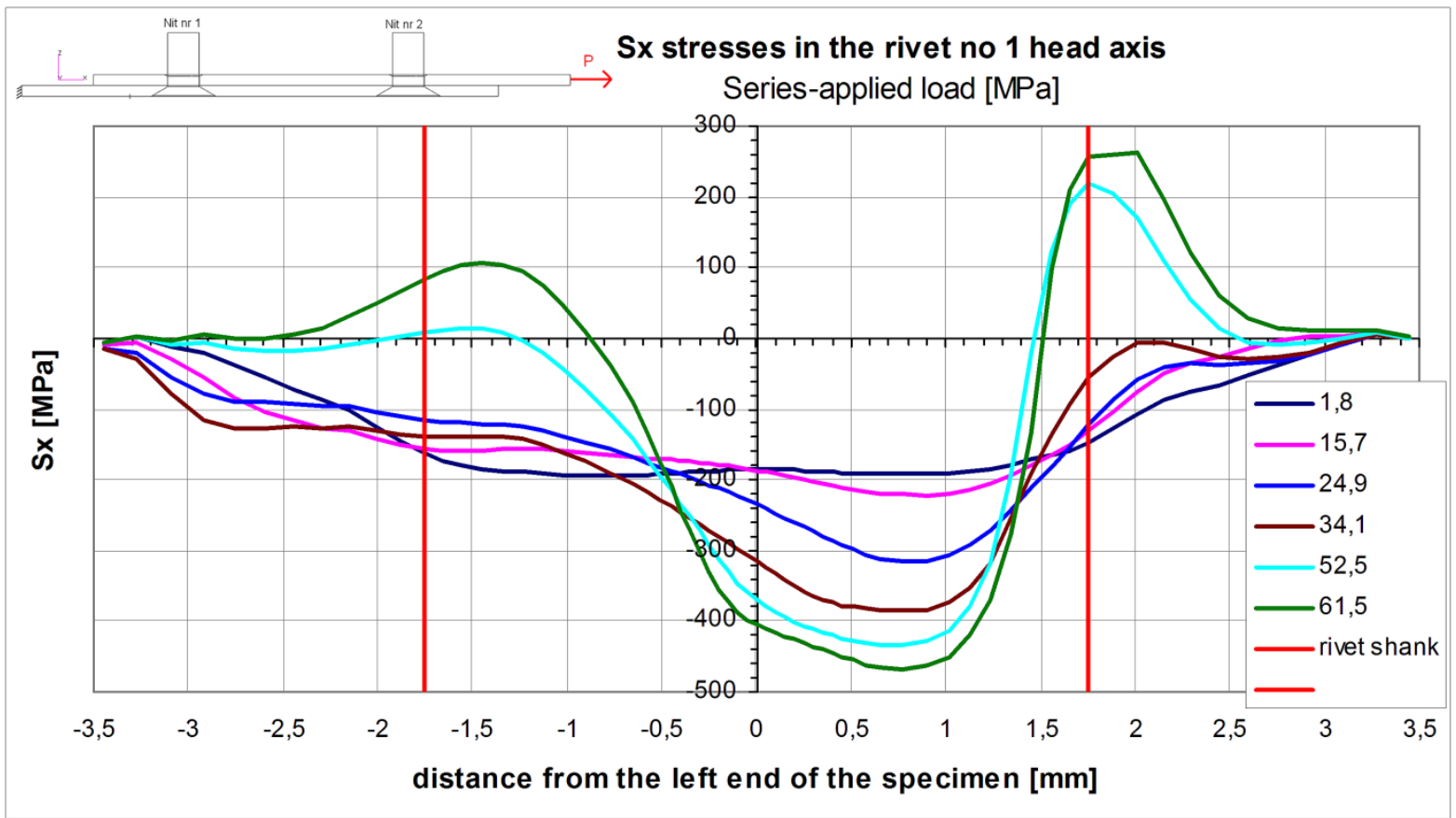

Fig. 11. Sx stresses (in tension direction) on manufactured head of rivet 1 on the specimen symmetry plane 


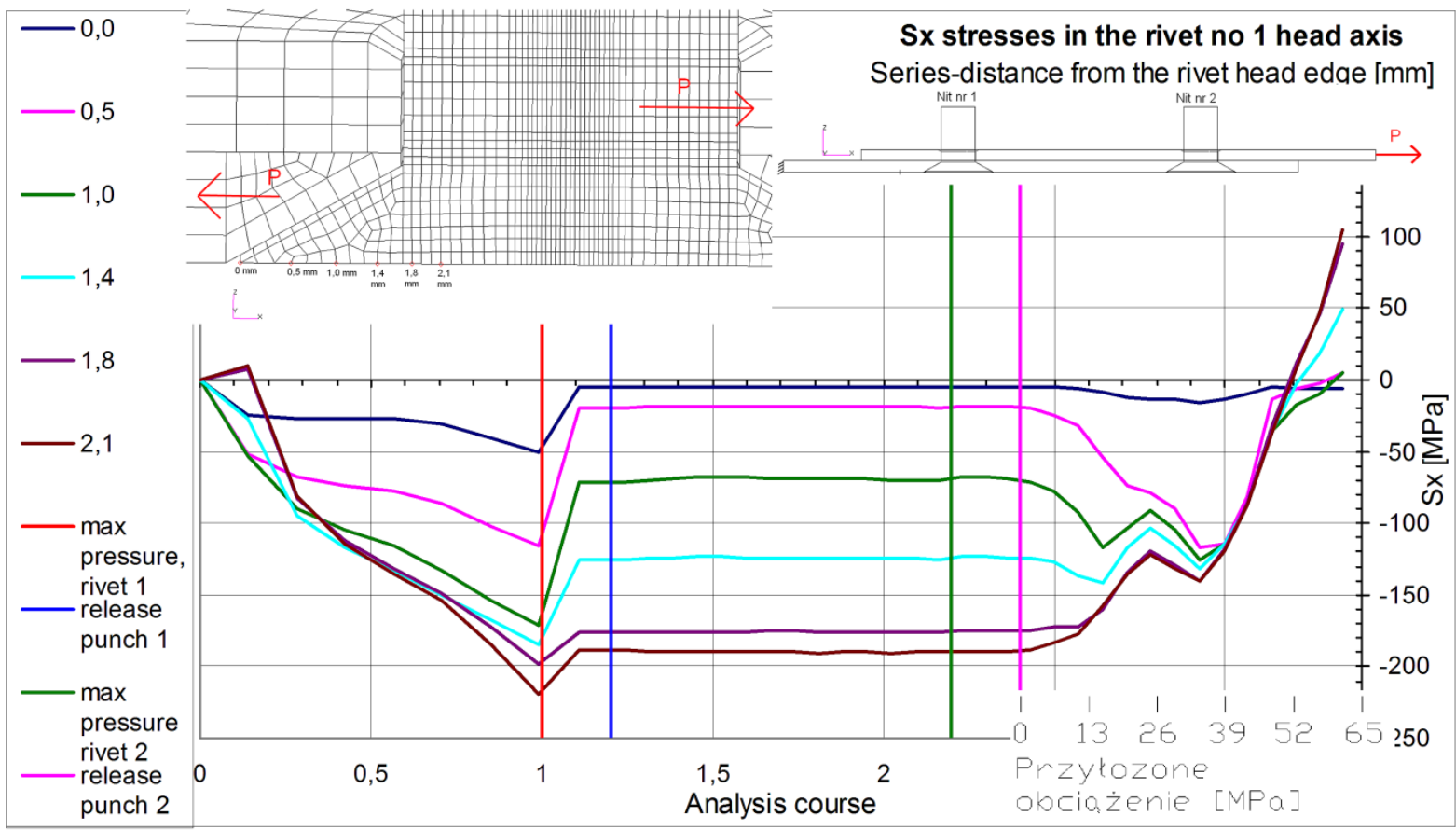

Fig. 12. Sx stresses during the analysis on selected nodes lying on manufactured head of rivet 1 , on the specimen symmetry plane

The nodes for which the graph (fig. 12) was drawn were marked in the small picture in the upper left corner of the graph. The graph relates to rivet 1, which was riveted at the beginning of the analysis. The graph covers the entire analysis.

At the beginning of the analysis, Sx stresses change rather quickly, which is associated with forming the driven head of rivet 1 . There is a relaxation of stresses when the punch of press 1 is released. During riveting rivet 2, stresses on the manufactured head of rivet 1 remain practically constant. This shows that the process of forming the driven head of one rivet practically does not interfere with forming others.

In the part of the graph which covers the tension phase there are a number of characteristic points.

Sx stresses on the node at the same edge of the rivet manufactured head are almost constant during tension of the joint.

In the node lying $0.5 \mathrm{~mm}$ from the heads edge, compressive stresses increase until applied tension reaches $34,1 \mathrm{MPa}$, then decrease to zero and reach a small positive value (tension).

In nodes 1 and 1,4 $\mathrm{mm}$ from the heads edge, compressive stresses increase until applied tension reaches $15,7 \mathrm{MPa}$, then decrease until applied tension reaches $24.9 \mathrm{MPa}$ and again increase till 34.1 MPa of applied tension. After that, stresses decrease to zero and become tensile.

The last two nodes (1,8 and 2,1 from the heads edge) lie under the rivet shank. For these, there is a relaxation of compressive stresses during tension of the joint, from the beginning to the value of 24,9 $\mathrm{MPa}$ of tension. After that, stresses increase slightly until applied load reaches $34.1 \mathrm{MPa}$ and then decrease to zero and reach significant values as tensile stresses.

For applied tension of 34,1 MPa, stress values in all marked nodes (except the one lying on the heads edge) are quite close and are almost equal between 39 and $48 \mathrm{MPa}$ of applied tension.

Figures 13-15 present Sx stresses and deformation in the vicinity of rivet 1 for the same values of applied tension as in the graph in figure $11(1,8 ; 15,7 ; 24,9 ; 34,1 ; 52,5 ; 61,5 \mathrm{MPa})$. Values of 15,$7 ; 24,9 ; 34,1 \mathrm{MPa}$ correspond to the characteristic points in fig. 12. 
Patran 2007 rib 27-Apr-10 16:08:08

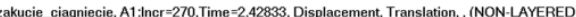

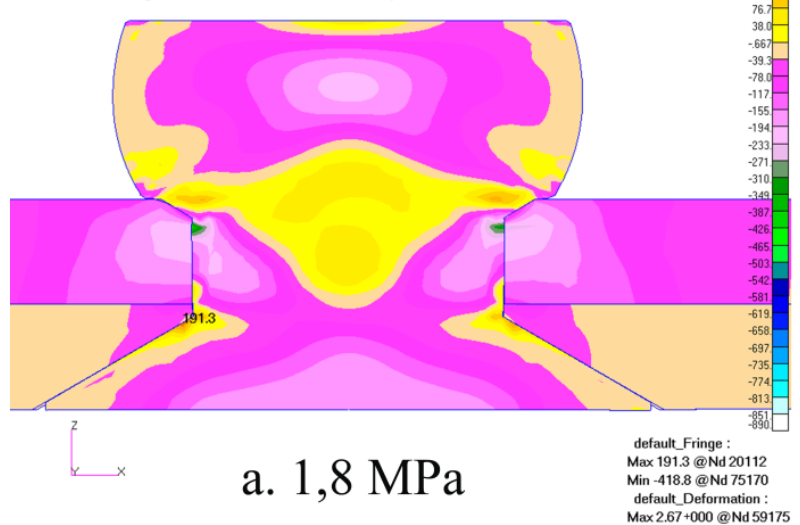

Patran 2007 r1b 27-Apr-10 16:08:43

7akucie ciagniecie, A1:Incr $=300$ Time $=264083$, Stress, Global System, XComp

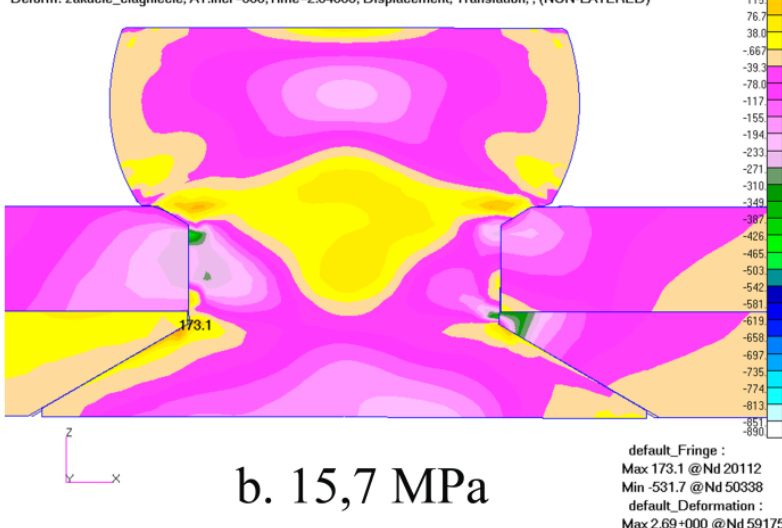

Fig. 13. Sx stresses and deformation in the vicinity of rivet 1 for applied tension equal a) 1,8 b) $15,7 \mathrm{MPa}$

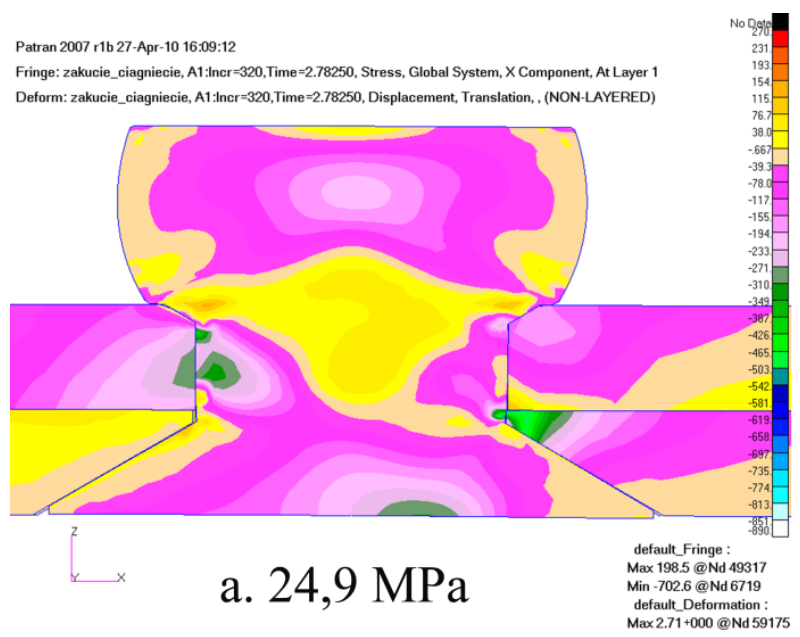

Patran 2007 r1b 27-Apr-10 16:09:4

Fringe: zakucie_ciagniecie, A1:Incr=340,Time=2.92417, Stress, Global System, X Component, At Layer 1 Deform: zakucie_ciagniecie, A1:Incr=340,Time=2.92417, Displacement, Translation, , (NON-LAYERED)

Translation, , (NON-LAYER

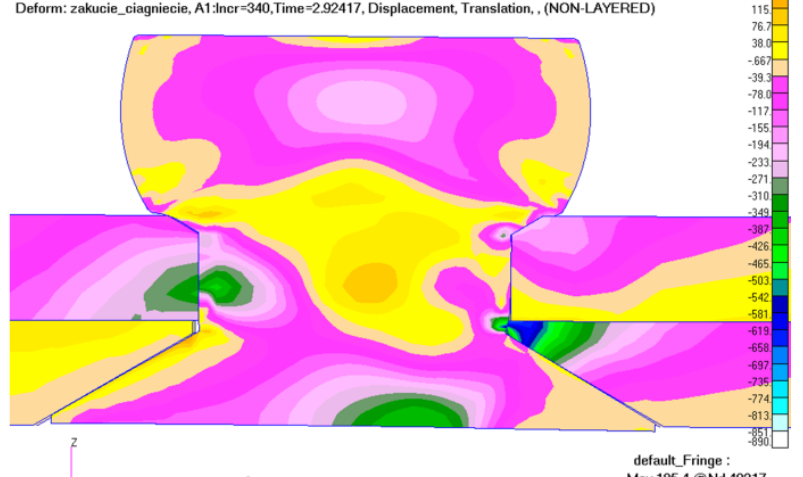

Fig. 14. Sx stresses and deformation in the vicinity of rivet 1 for applied tension equal a) 24,9 b) 34,1 MPa

Patran 2007 r1b 27-Apr-10 16:13:34

Fringe: zakucie_ciagniecie, A1:Incr=380,Time=3.20750, Stress, Global System, XComponent, At Layer Deform: zakucie_ciagniecie, A1:Incr=380,Time=3.20750, Displacement, Translation, , (NON-LAYERED)

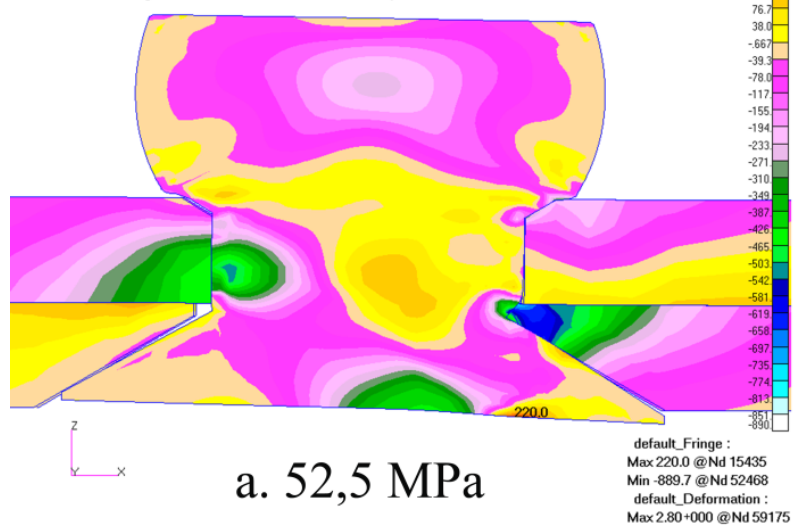

Patran 2007 16 27-Apr-10 16:14:37

Fringe: zakucie_ciagniecie,A1 Deform: zakucie_ciagniecie, A1:Incr=400,Time=3.34562, Displacement, Translation, , (NON-LAYERED)

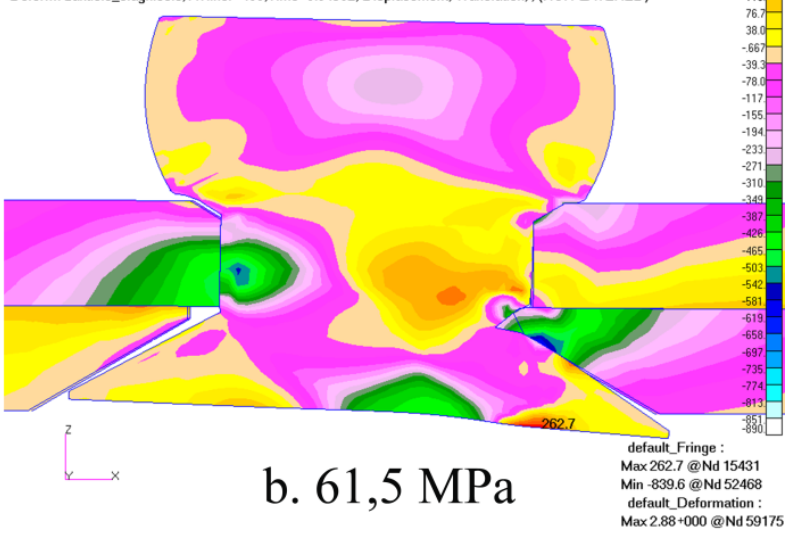

Fig. 15. Sx stresses and deformation in the vicinity of rivet 1 for applied tension equal a) 52,5 b) 61,5 $\mathrm{MPa}$ 
It is worth noticing that, for all mentioned characteristic points, deformation of the joint near the rivet is not significant, although for $34,1 \mathrm{MPa}$ of applied tension there is a small space between the shank of the rivet and outer (lower) sheet, on the left side in fig. $14 \mathrm{~b}$.

\section{CONCLUSION}

The paper presents the results obtained from the FEM calculations of the riveted lap joint loaded with tension. Stress distribution in the vicinity of the rivets was shown for the end of the riveting process and tension of the specimens. In the graph of Sx stresses as a function of applied load, for nodes lying on the manufactured head of the rivet, on the symmetry plane of the specimen (fig. 12), there are some characteristic points. Between these points the curves change their directions. The authors have not succeeded in determining reasons for such courses of stresses so far. It is not sure either whether these phenomena occur in reality or whether they result from the numerical model.

Experimental verification using strain gauges is planned. The FEM model will also be developed. It should cover the full length of the specimen and penetration should be eliminated. Also the mesh will be improved near the rivets.

The financial support from Ministry of Science and Higher Education under the contract number 59/EUR/2006/02 is gratefully acknowledged.

\section{REFERENCES}

[1] Szymczyk, E., Jachimowicz, J., Derewońko, A. (2008). Riveting Process SimulationUpsetting of the Mushroom Rivet. Journal of KONES.

[2] Müller, R., P., G. (1995). An experimental and analytical investigation on the fatigue behaviour of fuselage riveted lap joints. The significance of the rivet squeeze force, and a comparison of 2024-T3 and Glare 3. Ph.D. Thesis, Delft University of Technology.

[3] Rans, C., D. (2007). The Role of Rivet Installation on the Fatigue Performance of Riveted Lap Joint. Ph.D. Thesis, Carleton University Ottawa, Ontario. 